\title{
TOWARDS MEETING THE IATA-AGREED 1.5\% AVERAGE ANNUAL FUEL EFFICIENCY IMPROVEMENTS BETWEEN 2010 AND 2020: THE CURRENT PROGRESS BEING MADE BY U.S. AIR CARRIERS
}

\author{
Kit Sum CHO (D), Guanying LI (D), Nicholas BARDELL (D)* \\ School of Engineering, RMIT University, Melbourne, Victoria 3000, Australia
}

Received 23 December 2019; accepted 27 January 2020

\begin{abstract}
The purpose of this paper is to see if airlines in general, and U.S. air-carriers in particular, are meeting their IATA-agreed 1.5\% average annual fuel efficiency improvements between 2010 and 2020. To assess the fuel efficiency performance, a quantitative analysis was performed using data provided by ICAO, IATA and the U.S. Bureau of Transportation Statistics (BTS) Form 41 Schedules P 12(a) and T-2. The metric used to assess fuel efficiency is the one advanced by ICAO, namely Litres per Revenue Tonne Kilometre performed. Trends are examined over an extended timeframe to establish annual fuel efficiency improvements. The findings show that the overall performance of U.S. air-carriers from 2010 to 2018 has just met IATA's $1.5 \%$ target with a $1.52 \%$ year-upon-year annual fuel efficiency improvement, with domestic operations showing a greater level of improvement than international operations. Such performance suggests that the U.S.A, and by inference, the rest of the world, are just likely to meet their IATA target by 2020. This achievement has largely been made possible through industry's tremendous efforts to enhance aircraft engine technologies, implement operational improvements, and reduce airframe weight through the extensive application of composite materials.
\end{abstract}

Keywords: aviation, fuel efficiency, revenue tonne-kilometre, scheduled and non-scheduled service, U.S. air carriers.

\section{Introduction}

Commercial airlines and governments worldwide recognize the vital role which international aviation plays in global economic and social development. Since the turn of the millennium, global air traffic demand has grown significantly, driven by the availability of new flight routes and the emergence of low-cost carriers and major airline alliances (Lumbroso, 2019; Zhang et al., 2008). Forecasts from IATA (2018a) and other reputable sources such as Airbus (2019) and Boeing (2019) predict an annual compound growth rate of between $3.5 \%$ to $4.5 \%$ in both air passenger numbers and air cargo out to 2037. To ensure that international aviation continues to develop in a sustainable manner there are many challenges to address, not least the sector's continued reliance on fossil fuels and the associated damage that results to the environment from greenhouse gases such as carbon dioxide $\left(\mathrm{CO}_{2}\right)$ and other harmful emissions (Hassan, Pfaender, \& Mavris, 2018). Although aviation's contribution to global warming is relatively minor, accounting for approximately $2 \%-3 \%$ of total global $\mathrm{CO}_{2}$ emissions (Nelson \& Reddy, 2018), it is nonetheless projected to increase significantly as the public's appetite for air travel continues unchecked.

The International Air Transport Association (IATA) is the trade association for the world's airlines, currently representing some 290 airlines that equals $82 \%$ of total air traffic (IATA, 2019). In 2007 IATA introduced its vision of a net zero emissions future (IATA, 2007). Two years later, IATA's Board of Governors underlined their commitment to addressing aviation carbon emissions - with the collective agreement of the worldwide aviation industry - by proposing three sequential goals ${ }^{1}$ :

(i) $1.5 \%$ average annual fuel efficiency improvement between 2010 and $2020^{2}$.

\footnotetext{
1 This commitment was adopted by IATA at the 2010 AGM Resolution on Climate Change (CNG2020, n.d.)

2 A year later, the 37th Session of the International Civil Aviation Organization (ICAO, 2010) Assembly affirmed two main resolutions for aviation: to achieve an annual $2 \%$ average fuel efficiency improvement until 2020 and an aspirational 2\% improvement per annum from 2021 to 2050 , and to achieve carbon neutral growth from 2020 .
}

*Corresponding author. E-mail: nick.bardell@rmit.edu.au 
(ii) Carbon neutral growth from $2020^{3}$.

(iii) A reduction of $50 \%$ in net emissions by $2050 \mathrm{com}-$ pared to 2005 levels (IATA, 2009).

Furthermore, IATA, through its member airlines, and ICAO, through its 193 member states (ICAO, 2019), are implementing a broad range of practical measures ${ }^{4}$ to improve airline fuel efficiency and ensure the sustainability of the aviation industry. This accords with the United Nations' definition of a sustainable development as one that "meets current needs without compromising the ability of future generations to meet their needs" (Engelman, 2013).

However, the forecast growth in the number of people flying will see the industry's emissions continue to rise unless combatted by other means (Budd, Griggs, \& Howarth, 2013). Indeed, as Gössling and Upham (2009) noted, the main challenge facing the industry is whether or not the fuel efficiency improvements can keep up with the growth in demand for air transportation.

Hence the aim of this paper is to assess if airlines in general, and those in the U.S. in particular, are meeting the first of their IATA-agreed goals, namely achieving a 1.5\% average annual fuel efficiency improvement. This study further accounts for both domestic and international markets, and distinguishes between scheduled and non-scheduled flights, in an attempt to provide a comprehensive overview of how fuel efficiencies vary within different aviation sectors.

According to ICAO (2009), scheduled services are flights scheduled and performed for remuneration according to a published timetable, or so regular or frequent as to constitute a recognizably systematic series, which are open to direct booking by members of the public. A nonscheduled air service is a commercial air transport service performed as other than a scheduled air service. Though the terms non-scheduled and charter (i.e. a contractual arrangement between an air carrier and an entity hiring or leasing its aircraft) have come to be used interchangeably, it should be noted that not all commercial non-scheduled operations are charter flights.

Attention is focused here on U.S. air carriers primarily because:

(i) The U.S. is home to the largest aviation market in the world, in terms of revenue tonne kilometres (IATA, 2018a), and

(ii) the only freely-available source of commercial aviation data that includes both traffic volumes and fuel consumption usage belongs to the U.S. Bureau of Transportation Statistics (BTS Schedule P-12(a) 2019, BTS Schedule T-2, 2019).

\footnotetext{
3 More recently, ICAO has adopted a new aircraft $\mathrm{CO}_{2}$ emissions standard which will reduce the impact of aviation greenhouse gas emissions on the global climate. This represents the world's first global design certification standard governing $\mathrm{CO}_{2}$ emissions for any industry sector, and will apply to new aircraft type designs from 2020, and to aircraft type designs already in-production as of 2023 (ICAO, 2017).

4 These measures include improvements in aircraft technology and operations, more efficient use of airspace, and the increasing uptake of sustainable alternative fuels for aviation.
}

With reference to (i), it must be pointed out that the U.S.A. only accounts for approximately $20 \%$ of total worldwide aviation activity $^{5}$ (IATA, 2018b; IATA, 2018c). Hence whilst the trends in U.S. aviation fuel efficiency that are reported here may not be fully reflective of other regions in the world, they should nonetheless provide a broad indication of what might be expected. With reference to (ii), it is regrettable that other aviation-intensive world markets, such as those in Europe, S.E. Asia and China, do not publish such fuel and traffic volume information. This limitation has previously been noted by other researchers, such as Peeters, Middel, and Hoolhorst $(2005)^{6}$, and the dearth of publicly available information about aviation fuel efficiency continues to frustrate further research efforts.

\section{Fuel efficiency metric}

Aircraft fuel efficiency performance can encompass a wide range of capabilities such as range, payload, speed, altitude etc. As a result, many different studies have been conducted, ranging from comparisons between different aircraft types (Lee et al., 2001; Babikian, Lukachko, \& Waitz, 2002) to the energy efficiency of entire airlines (Miyoshi \& Merkert, 2010; Cui \& Li, 2015, 2016). Seminal work by Nangia (2006) and Hileman et al. (2008) demonstrated that the productivity of aviation could be quantified in its simplest form as the "product of passenger and cargo payload and the distance travelled while the cost is examined in terms of fuel energy consumed". They termed this metric the Payload Fuel Energy Efficiency (PFEE). A similar fuel efficiency metric was adopted by ICAO (2010) in Article A3719, Item 4, defined as the volume of fuel used per Revenue Tonne-Kilometre (RTK) performed. As such, this metric represents the amount of fuel in litres that is required to move one tonne of revenue payload a distance of one kilometre by air. The main advantages of using such a simple measure are:

- Only a limited amount of input data is required, improving the chances of success;

- A given fleet of aircraft will generally be represented by a mix of new, efficient aircraft types, and older, less efficient models. The ICAO metric will hence provide an overall fleet average;

- The ICAO metric represents an absolute measure of how much payload has actually been transported in a given time period ${ }^{7}$, and how much fuel was expended in the process.

5 In 2018 the North American passenger market (RPK) and air cargo market (FTK) accounted for $22.4 \%$ and $23.7 \%$ respectively of the world market.

6 "Although world aviation traffic statistics are available from several sources, relevant fuel consumption data for commercial aviation are hardly available in an appropriate format." Peeters, Middel, and Hoolhorst (2005)

7 This is preferable to using a relative measure, such as the passenger or cargo load factor, which is not a technical property of the aircraft but more a measure of the operational efficiency of the airline. 
It is also noted that an aircraft's trip fuel burn can vary significantly as a function of both the payload carried and the mission range for a given trip, along with a variety of other operational factors that cannot easily be predicted ${ }^{8}$. However, all these complicating factors are accounted for in the ICAO metric, since only the gross fuel consumption in a given time period is required.

In the context of commercial aviation, the unit of payload depends on whether the aircraft is being used to transport passengers, freight/post/express, or a combination of these. Attention is paid to the following three types of service:

- cargo payload (freight and mail) carried on scheduled or non-scheduled all-cargo dedicated freighter aircraft, e.g., Boeing 777F;

- cargo payload (freight and mail) carried on scheduled or non-scheduled passenger aircraft (this is sometimes referred to as belly-freight), e.g., Airbus A330-200;

- passenger payload carried on scheduled or nonscheduled passenger aircraft, e.g., Airbus A380-800.

At this stage it is important to recall two standard measures frequently used in aviation:

- Air passenger traffic is measured in RPKs, Revenue Passenger-Kilometres. A revenue passengerkilometre is generated when one revenue-paying passenger is transported one kilometre.

- Air cargo traffic is measured in RTKs, Revenue Tonne-Kilometres. A revenue tonne-kilometre is generated when a metric tonne of revenue load is carried one kilometre.

Hence, to reflect the productivities of both passenger transport and cargo, it is necessary to convert the number of RPKs to RTKs so that the overall productivity is rendered in consistent tonne units. This conversion requires an average weight for passengers, including their luggage, assumed here to be $200 \mathrm{lbf}(90.7 \mathrm{~kg})$ per passenger (BTS Schedule T100, 2019). The ICAO fuel efficiency metric, denoted here by the symbol $\eta$, can then be formulated as:

$$
\eta=V_{\text {fuel }} /\left(R T K_{\text {pax }}+R T K_{\text {freight }}+R T K_{\text {mail }}\right),
$$

where $V_{\text {fuel }}$ is the volume in litres of fuel required to deliver the service performed; $\eta$ has units of L/RTK and is used herein for all the subsequent analyses of fuel efficiency.

\section{Methodology}

This research methodology adopted here is categorized as quantitative research, based on secondary data, obtained from the U.S. DoT Schedules T-2 and P-12(a) (BTS Sched-

\footnotetext{
8 These operational factors include the cruising altitude (often decided by ATC controllers, not the aircrew), en-route traffic conditions (which means the cruising altitude can change several times during a single flight), airport restrictions on climb-out to minimise the noise footprint (which means more fuel is consumed because the flaps must be extended for a longer time), and, of course, the fact that in straight and level cruise conditions, the fuel consumption reduces as the plane gets lighter as it gradually burns its own fuel (which is a key assumption used in deriving the Breguet Range equation).
}

ule T-100, 2019). All subsequent data manipulation follows standard analytical procedures, as described in Sections 2.3-2.5 and Table 1.

The Bureau of Transportation Statistics is a U.S. Department of Transport database freely available to the general public that provides a wealth of data on commercial aviation, multimodal freight, and transportation economics (BTS Schedule P-12(a) 2019, BTS Schedule T-2 2019). The Air Carrier Statistics database, referred to as Form 41 Traffic, contains domestic and international airline market and segment data. Certificated U.S. air carriers report monthly air carrier traffic information using Form T-100. The data is collected by the Office of Airline Information, Bureau of Transportation Statistics. Durso (2007) provides a comprehensive overview of the Form 41 database and the interested reader is encouraged to consult her work.

\subsection{Schedule T-2: U.S. air carrier traffic and capacity statistics by aircraft type}

The Schedule T-2 database (BTS Schedule T-2, 2019) summarizes the T-100 traffic data reported by U.S. air carriers only. The quarterly summary is compiled by aircraft types/configurations, carrier entities (geographical regions in which a carrier operates), and service classes, and includes available seat miles (ASMs), available ton miles (ATMs), revenue passenger miles (RPMs), revenue ton miles (RTMs), and aircraft fuels issued in U.S. gallons ${ }^{9}$. For a given single year of operation, this information generally amounts to thousands of lines of numerical data (5,000-6,500).

\subsection{Schedule P-12(a) (all carriers)}

Schedule P-12(a) (BTS Schedule P-12(a), 2019) contains monthly reported fuel costs, and U.S. gallons of fuel consumed, by air carrier and category of fuel use, including scheduled and non-scheduled services for domestic and international traffic regions.

\subsection{Data filtering and manipulation - service class}

According to the T-100 Traffic Reporting Guide (2007), the data in Schedule T-2 is reported in different service classes; the ones of interest in this study are limited to:

F - Scheduled Passenger Service (includes Freight/

Mail in the Belly),

G - Scheduled ALL Cargo Service (NO Passengers),

L - Non-Scheduled Passenger Service (includes Freight/Mail in the Belly),

N - Non-Scheduled Military Passenger Service by U.S. Carriers (includes Freight/Mail in the Belly),

\footnotetext{
9 It is noted that fuel data can only be found in Schedule P-12(a), although it should appear in Schedule T-2 in the column "AIRCRAFT FUELS_921" - most likely this column is suppressed due to company confidentiality issues, and only fleet-wide totals by geographical region are provided in Schedule P-12(a).
} 
P - Non-Scheduled ALL Cargo Service (NO Passengers), and

R - Non-Scheduled Military ALL Cargo Service by U.S. Carriers (NO Passengers).

\subsection{Data filtering and manipulation - Carrier Region}

Carrier Region includes $A \sim$ Atlantic, $D \sim$ Domestic, $I \sim$ International, $L \sim$ Latin America, $P \sim$ Pacific and $S \sim$ System. No information could be found to explain what the categories $I \sim$ International and $S \sim$ System referred to - both contained sparse data and probably result from incorrect data entries in the T-100 database. Both categories were omitted from this work. Hence, it is important for the reader to understand that when the term "International region", is used in this work, it refers to the summation of data entries from the $A \sim$ Atlantic, $L \sim$ Latin America, and $P \sim$ Pacific regions.

\subsection{Data filtering and manipulation - filtered data}

The Schedule T-2 data used in the current work were filtered year-by-year according to the service class and carrier regions described above in section 2.3 and 2.4 respectively. This reduces the number of numerical records and for the work reported here, although different years contained different volumes of data, no single year contained less than 2,500 entries. The following columns were then processed:

\section{REV_PAX_MILES_140}

REV_TON_MILES_240 (total RTM - freight, mail and passengers performed in a given time period)

REV_TON_MILES_FREIGHT_247

REV_TON_MILES_MAIL_249
Each column identified above of suitably filtered data is then summed, and rendered into the corresponding SI unit, noting:

- The weight of both freight and mail is given in short tons. 1 short ton $=907 \mathrm{~kg}$ or 0.907 tonnes. Freight and mail are combined here under the heading "cargo";

- Distances are quoted in statute miles. 1 statute mile $=1.6093 \mathrm{~km}$;

- Fuel volumes are quoted in U.S. gallons. 1 U.S. gallon $=3.7854$ Litres.

With reference to Equation (1), Schedule T-2 is filtered for the passenger RPMs for service classes $F, L$ and $N$ across domestic and international regions for both scheduled and non-scheduled services. The RPMs are then multiplied by the average passenger weight to give RTMs, and then converted to SI units to give RTK $_{\text {pax }}$. Similar filtering applies to freight and mail, noting such cargo payload can occur as payload carried exclusively on freighter aircraft (extracted from service classes $G, P$ and $R$ ) and cargo payload carried on passenger aircraft in the belly hold (extracted from service classes $F, L$ and $N$ ). This yields the RTM values for freight and mail, which can then be rendered into the corresponding SI values for $R T K_{\text {freight }}$ and $R T K_{\text {mail }}$.

A sample calculation for domestic U.S. air carriers in 2007 is presented in Table 1 to demonstrate the stages of the analysis conducted herein. The steps are self-explanatory and show how the total RTK and fuel volume are established for all services (scheduled + non-scheduled). The values shown in Table 1 for items [3], [6] and [7] are shown highlighted in bold in Tables 3, 2, and 4 respectively.

Table 1. RTK and fuel volumes for both scheduled and non-scheduled U.S. air carriers, Domestic region, 2007

\begin{tabular}{|c|c|c|c|}
\hline ID & Summed values & $($ BTS Schedule T-2 2019)* & SI Converted values \\
\hline$[1]$ & $\begin{array}{l}\text { REV_PAX_MILES_140 } \\
\text { (service class: } F, L \text { and } N \text { ) }\end{array}$ & $\mathrm{RPM}_{\mathrm{pax}}=607,563,958,736$ & \\
\hline$[2]$ & $\begin{array}{l}\text { RPM converted to RTM } \\
200 \mathrm{lbf}(90.7 \mathrm{~kg}) \text { per passenger }\end{array}$ & $\mathrm{RPT}_{\mathrm{pax}}=60,756,395,874$ & $\mathrm{RTK}_{\mathrm{pax}}=88.7027 \times 10^{9}$ \\
\hline$[3]$ & $\begin{array}{l}\text { REV_TON_MILES_240 } \\
\text { (This is the sum of [2], [4], and [5]): }\end{array}$ & $\mathrm{RTM}_{\text {total }}=75,898,917,209$ & $\mathrm{RTK}_{\text {total }}=110.8103 \times 10^{9}$ \\
\hline$[4]$ & $\begin{array}{l}\text { REV_TON_MILES_FREIGHT_247 } \\
\text { (service class: } F, L, N \text {, and } G, P, R \text { ) }\end{array}$ & $\mathrm{RTM}_{\text {freight }}=14,612,308,613$ & $\mathrm{RTK}_{\text {freight }}=21.3336 \times 10^{9}$ \\
\hline$[5]$ & $\begin{array}{l}\text { REV_TON_MILES_MAIL_249 } \\
\text { (service class: } F, L, N \text {, and } G, P, R \text { ) }\end{array}$ & $\mathrm{RTM}_{\text {mail }}=530,212,722$ & $\mathrm{RTK}_{\text {mail }}=0.7741 \times 10^{9}$ \\
\hline$[6]$ & $\begin{array}{l}\text { Total fuel volume consumed by U.S. carriers } \\
\text { operating domestically in } 2007 . \\
\text { (BTS Schedule P-12(a), 2019) }\end{array}$ & $\begin{array}{l}13.6817 \times 10^{9} \\
\text { U.S. gallons }\end{array}$ & $51.7908 \times 10^{9}$ Litres \\
\hline [7] & Fuel efficiency from Equation (1) & & $\begin{array}{c}=[6] /([2]+[4]+[5]) \\
=\left(51.7908 \times 10^{9}\right) /\left(110.8103 \times 10^{9}\right) \\
=\mathbf{0 . 4 6 7 4} \text { L/RTK }\end{array}$ \\
\hline
\end{tabular}

${ }^{*}$ Filtering was performed to include only Region $D$.

Note: The results shown in bold font in Table 1 are highlighted in Tables 2, 3 and 4 for traceability. 


\section{Results}

The fuel volumes used across domestic and international regions on an annual basis for both scheduled and nonscheduled services are sourced from BTS Schedule P-12(a) (2019), converted into litres, and presented in Table 2.

Likewise, the RTK values, denoting the productivity across domestic and international regions for both scheduled and non-scheduled services, are presented in Table 3 on an annual basis.

Finally, the ICAO fuel efficiency metric, $\eta$, is determined by dividing the fuel volumes presented in Table 2 by the corresponding RTK values shown in Table 3.
The data from Table 4 is plotted graphically as follows: Figure 1 shows how the fuel efficiency has changed [improved] with time for all services operated domestically and internationally by U.S. air carriers between 2005-2018; the component data for the scheduled services and the nonscheduled services is displayed in Figures 2 and 3 respectively. Since the metric used for fuel efficiency is expressed in terms of litres per RTK, then the smaller the number for $\eta$, the better the performance in fuel efficiency.

Despite the lack of a uniform reduction in $\eta$ every year, the general downward trend shown in Figure 1 clearly shows a definite improvement in fuel efficiency, $\eta$,

Table 2. Annual fuel consumption (Litres x $10^{9}$ ) of U.S. air carriers on an annual basis

\begin{tabular}{|c|c|c|c|}
\hline \multirow{2}{*}{ Year } & \multicolumn{3}{|c|}{ Non-Scheduled Service } \\
\cline { 2 - 4 } & Dom & Intl & Total \\
\hline 2005 & 2.6180 & 3.5630 & 0.1543 \\
\hline 2006 & 0.5555 & 0.0185 & 5.5736 \\
\hline 2007 & 0.5851 & 0.9394 & 0.5244 \\
\hline 2008 & 0.8184 & 0.5658 & 3.3845 \\
\hline 2009 & 0.7260 & 2.4026 & 3.1286 \\
\hline 2010 & 0.7578 & 3.0090 & 3.7672 \\
\hline 2011 & 0.7840 & 3.7915 & 4.5754 \\
\hline 2012 & 0.7635 & 3.3505 & 4.1140 \\
\hline 2013 & 0.6844 & 2.7963 & 3.4807 \\
\hline 2014 & 0.6280 & 0.5967 & 2.2251 \\
\hline 2015 & 0.7094 & 1.6364 & 0.3458 \\
\hline 2016 & 0.7809 & 1.5800 & 2.3610 \\
\hline 2017 & 0.9358 & 0.8416 & 2.7770 \\
\hline 2018 & 1.1440 & 0.1906 & 3.3346 \\
\hline
\end{tabular}

\begin{tabular}{|c|c|c|}
\hline \multicolumn{3}{|c|}{ Scheduled Service } \\
\hline Dom & Intl & Total \\
\hline 50.2861 & 19.0796 & 69.3657 \\
\hline 49.2838 & 19.7610 & 69.0447 \\
\hline 49.2058 & 20.5472 & 69.7530 \\
\hline 47.2018 & 20.8534 & 68.0556 \\
\hline 42.1975 & 19.2549 & 61.4523 \\
\hline 41.8541 & 19.8602 & 61.7143 \\
\hline 40.9896 & 20.8992 & 61.8888 \\
\hline 38.7550 & 21.2785 & 60.0336 \\
\hline 38.4450 & 21.7608 & 60.2058 \\
\hline 38.9617 & 22.3320 & 61.2941 \\
\hline 40.6598 & 22.6682 & 63.3284 \\
\hline 42.2728 & 22.2480 & 64.5212 \\
\hline 42.9281 & 22.5414 & 65.4698 \\
\hline 44.8431 & 22.7901 & 67.6332 \\
\hline & &
\end{tabular}

\begin{tabular}{|c|c|c|}
\hline \multicolumn{3}{|c|}{$\begin{array}{c}\text { All Services } \\
\text { (Scheduled + Non-Scheduled } \\
\text { Services) }\end{array}$} \\
\hline Dom & Intl & Total \\
\hline 52.9041 & 2.6159 & 75.5201 \\
\hline 51.8389 & 22.7791 & 74.6184 \\
\hline 51.7908 & 23.4866 & 75.2774 \\
\hline 48.0206 & 23.4192 & 71.4398 \\
\hline 42.9235 & 21.6575 & 64.5810 \\
\hline 42.6120 & 22.8696 & 65.4815 \\
\hline 41.7735 & 24.6907 & 66.4642 \\
\hline 39.5185 & 24.6290 & 64.1476 \\
\hline 39.1298 & 24.5571 & 63.6869 \\
\hline 39.5901 & 23.9291 & 63.5188 \\
\hline 41.3692 & 24.3046 & 65.6742 \\
\hline 43.0537 & 23.8284 & 66.8821 \\
\hline 43.8638 & 24.3830 & 68.2468 \\
\hline 45.9859 & 24.9803 & 70.9662 \\
\hline & & \\
\hline
\end{tabular}

Table 3. Revenue Tonne-kilometres (RTKs $\times 10^{9}$ ) for U.S. air carriers on an annual basis

\begin{tabular}{|c|c|c|c|}
\hline \multirow{2}{*}{ Year } & \multicolumn{3}{|c|}{ Non-Scheduled Service } \\
\cline { 2 - 4 } & Dom & Intl & Total \\
\hline 2005 & 4.0824 & 4.3335 & 8.4159 \\
\hline 2006 & 3.4946 & 3.8239 & 7.3186 \\
\hline 2007 & 3.2916 & 3.6512 & 6.9427 \\
\hline 2008 & 2.4053 & 2.1668 & 4.5721 \\
\hline 2009 & 1.8141 & 1.8683 & 3.6824 \\
\hline 2010 & 1.8610 & 2.3544 & 4.2154 \\
\hline 2011 & 1.6621 & 2.4714 & 4.1335 \\
\hline 2012 & 1.8605 & 2.0064 & 3.8669 \\
\hline 2013 & 2.0124 & 2.5103 & 4.5228 \\
\hline 2014 & 2.3564 & 2.7049 & 5.0613 \\
\hline 2015 & 2.7810 & 3.4092 & 6.1903 \\
\hline 2016 & 3.1098 & 3.2853 & 6.3951 \\
\hline 2017 & 4.2843 & 3.3468 & 7.6311 \\
\hline 2018 & 5.1631 & 3.2609 & 8.4240 \\
\hline
\end{tabular}

\begin{tabular}{|c|c|c|}
\hline \multicolumn{3}{|c|}{ Scheduled Service } \\
\hline Dom & Intl & Total \\
\hline 104.1350 & 49.9161 & 154.0510 \\
\hline 104.8494 & 53.3636 & 158.2129 \\
\hline 107.5188 & 55.8152 & 163.3339 \\
\hline 102.8236 & 56.4234 & 159.2470 \\
\hline 96.2980 & 52.3289 & 148.6269 \\
\hline 98.8914 & 58.0693 & 156.9607 \\
\hline 100.0907 & 59.2481 & 159.3388 \\
\hline 100.9470 & 59.3575 & 160.3045 \\
\hline 102.2248 & 58.9923 & 161.2171 \\
\hline 105.1303 & 60.1573 & 165.2875 \\
\hline 110.1931 & 60.3723 & 170.5654 \\
\hline 114.8584 & 60.8541 & 175.7125 \\
\hline 119.1150 & 64.6228 & 183.7378 \\
\hline 124.8420 & 67.1757 & 192.0176 \\
\hline & &
\end{tabular}

\begin{tabular}{|c|c|c|}
\hline \multicolumn{3}{|c|}{$\begin{array}{c}\text { All Services } \\
\text { (Scheduled + Non-Scheduled } \\
\text { Services) }\end{array}$} \\
\hline Dom & Intl & Total \\
\hline 108.2174 & 54.2495 & 162.4669 \\
\hline 108.3440 & 57.1875 & 165.5315 \\
\hline 110.8103 & 59.4663 & 170.2766 \\
\hline 105.2289 & 58.5902 & 163.8191 \\
\hline 98.1122 & 54.1972 & 152.3093 \\
\hline 100.7524 & 60.4237 & 161.1761 \\
\hline 101.7528 & 61.7195 & 163.4723 \\
\hline 102.8075 & 61.3639 & 164.1714 \\
\hline 104.2373 & 61.5026 & 165.7399 \\
\hline 107.4867 & 62.8622 & 170.3488 \\
\hline 112.9741 & 63.7816 & 176.7557 \\
\hline 117.9683 & 64.1394 & 182.1076 \\
\hline 123.3993 & 67.9696 & 191.3689 \\
\hline 130.0050 & 70.4366 & 200.4416 \\
\hline & & \\
\hline
\end{tabular}


Table 4. Fuel Efficiency Values, $\eta$ (Litres/RTK), for U.S. air carriers on an annual basis

\begin{tabular}{|c|c|c|c|}
\hline \multirow{2}{*}{ Year } & \multicolumn{3}{|c|}{ Non-Scheduled Service } \\
\cline { 2 - 4 } & Dom & Intl & Total \\
\hline 2005 & 0.6413 & 0.8161 & 0.7313 \\
\hline 2006 & 0.7313 & 0.7894 & 0.7616 \\
\hline 2007 & 0.7854 & 0.8051 & 0.7957 \\
\hline 2008 & 0.3402 & 1.1841 & 0.7403 \\
\hline 2009 & 0.4002 & 1.2860 & 0.8496 \\
\hline 2010 & 0.4072 & 1.2780 & 0.8937 \\
\hline 2011 & 0.4717 & 1.5341 & 1.1069 \\
\hline 2012 & 0.4104 & 1.6699 & 1.0639 \\
\hline 2013 & 0.3401 & 1.1139 & 0.7696 \\
\hline 2014 & 0.2665 & 0.5903 & 0.4396 \\
\hline 2015 & 0.2551 & 0.4800 & 0.3790 \\
\hline 2016 & 0.2511 & 0.4809 & 0.3692 \\
\hline 2017 & 0.2184 & 0.5503 & 0.3639 \\
\hline 2018 & 0.2216 & 0.6718 & 0.3958 \\
\hline
\end{tabular}

\begin{tabular}{|c|c|c|}
\hline \multicolumn{3}{|c|}{ Scheduled Service } \\
\hline Dom & Intl & Total \\
\hline 0.4829 & 0.3822 & 0.4503 \\
\hline 0.4700 & 0.3703 & 0.4364 \\
\hline 0.4576 & 0.3681 & 0.4271 \\
\hline 0.4591 & 0.3696 & 0.4274 \\
\hline 0.4382 & 0.3680 & 0.4135 \\
\hline 0.4232 & 0.3420 & 0.3932 \\
\hline 0.4095 & 0.3527 & 0.3884 \\
\hline 0.3839 & 0.3585 & 0.3745 \\
\hline 0.3761 & 0.3689 & 0.3734 \\
\hline 0.3706 & 0.3712 & 0.3708 \\
\hline 0.3690 & 0.3755 & 0.3713 \\
\hline 0.3680 & 0.3656 & 0.3672 \\
\hline 0.3604 & 0.3488 & 0.3563 \\
\hline 0.3592 & 0.3393 & 0.3522 \\
\hline & & \\
\hline
\end{tabular}

\begin{tabular}{|c|c|c|}
\hline \multicolumn{3}{|c|}{$\begin{array}{c}\text { All Services } \\
\text { (Scheduled + Non-Scheduled } \\
\text { Services) }\end{array}$} \\
\hline Dom & Intl & Total \\
\hline 0.4889 & 0.4169 & 0.4648 \\
\hline 0.4785 & 0.3983 & 0.4508 \\
\hline $\mathbf{0 . 4 6 7 4}$ & 0.3950 & 0.4421 \\
\hline 0.4563 & 0.3997 & 0.4361 \\
\hline 0.4375 & 0.3996 & 0.4240 \\
\hline 0.4229 & 0.3785 & 0.4063 \\
\hline 0.4105 & 0.4000 & 0.4066 \\
\hline 0.3844 & 0.4014 & 0.3907 \\
\hline 0.3754 & 0.3993 & 0.3843 \\
\hline 0.3683 & 0.3807 & 0.3729 \\
\hline 0.3662 & 0.3811 & 0.3716 \\
\hline 0.3650 & 0.3715 & 0.3673 \\
\hline 0.3555 & 0.3587 & 0.3566 \\
\hline 0.3537 & 0.3546 & 0.3540 \\
\hline
\end{tabular}

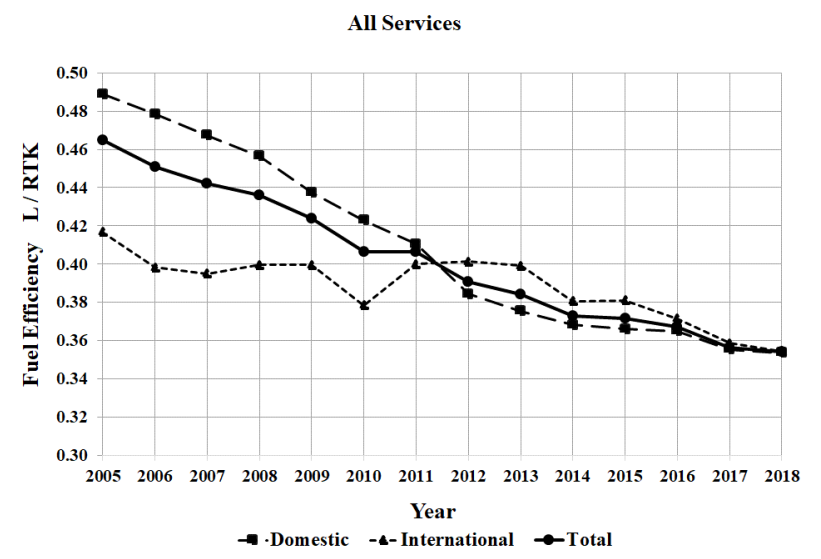

Figure 1. Domestic, international, and total Fuel Efficiency Values $\eta$ (L/RTK) for all U.S. air carriers on an annual basis: 2005-2018

over time. The annual percentage improvement in fuel efficiency can be gauged by using a simple difference technique applied to each year's data. However, the values for each year can fluctuate considerably and finding a single figure to represent a year-on-year improvement is difficult. An alternative method to obtain the average annual percentage improvement in $\eta$ over the 9 years from 2010 to 2018 , in accordance with the title problem, is to use the standard compound annual growth rate formula given by Equation (2).

$$
\eta_{2018}=\eta_{2010}(1+x \%)^{9}
$$

Although this simple measure assumes uniform compound growth, and hides fluctuations such as the global financial crisis, it nonetheless provides a good indication of the longer term average improvement rate for the in- dustry. Table 5 presents the solution for $x$ in Equation (2) for domestic, international, and total U.S. air carrier fleets over the 9 years from 2010 to 2018. The negative number assigned to the percentage growth $x$ indicates a year-onyear reduction [improvement].

Table 5. Domestic, international, and total U.S. air carrier fleet fuel efficiency improvements on an annual basis from 2010 to 2018

\begin{tabular}{|c|c|c|c|c|}
\hline \multirow{2}{*}{ Year } & \multicolumn{2}{|c|}{$\begin{array}{c}\text { All Services (Scheduled and Non- } \\
\text { Scheduled Flights) }\end{array}$} & \multirow{2}{*}{ Source } \\
\cline { 2 - 4 } & $\begin{array}{c}\text { Domestic } \\
{[\text { Litres/RTK] }]}\end{array}$ & $\begin{array}{c}\text { Intl } \\
\text { [Litres/RTK] }\end{array}$ & $\begin{array}{c}\text { Total } \\
\text { [Litres/RTK] }\end{array}$ & \\
\hline 2010 & 0.4229 & 0.3785 & 0.4063 & Table 4 \\
\hline 2018 & 0.3537 & 0.3546 & 0.3540 & Table 4 \\
\hline $\mathrm{x}$ & $-1.97 \%$ & $-0.72 \%$ & $-1.52 \%$ & Eqn (2) \\
\hline
\end{tabular}

Although the overall total annual fuel efficiency improvement over the past 9 years is $1.52 \%$, perhaps of more significance is the fact that U.S. international aviation fuel efficiency has improved by only $0.72 \%$ per annum between 2010 and 2018, well below IATA's 1.5\% target (CNG2020, n.d.), while domestic U.S. aviation has improved by a more impressive $1.97 \%$ per annum ${ }^{10}$. This suggests:

1. there is an increased uptake of more efficient aircraft and/or other efficiency-improving changes in the domestic U.S. aviation market, such as increased passenger load factors year-on-year, and

2. international operations are already relatively

10 If the data for the full 14-year time span illustrated here (from 2005 to 2018) is utilised, the corresponding annual fuel efficiency improvement values are: Total, $-1.93 \%$; international, $-1.15 \%$; and domestic, $-2.28 \%$. 
efficient and any efficiency gains made in this market have less of an overall impact.

These year-on-year figures certainly imply that for the time being the fuel efficiency of U.S. air carriers is just keeping pace with the increased growth in air travel. It is also interesting to note from Table 2 that although Domestic RTKs always exceed International RTKs, the fuel efficiency trends shown in Figure 1 suggest U.S. domestic operations are generally much less fuel efficient. This has been noted previously by Bardell and Yue (2018), who showed that a large quantity of domestic flights in the U.S.A. occur over relatively short distances, and hence incur a fuel penalty.

Figures 2 and 3 show the contribution the scheduled and non-scheduled sectors respectively make to the total fuel efficiency shown in Figure 1. Clearly, scheduled flights dominate commercial U.S. air traffic and the data underlying Figure 2 also makes the main contribution to Figure 1. The effects of the global financial crisis (GFC) are apparent around 2009-2011. As reported by IATA (2010), "Airlines responded to the severity of the recession with an unprecedented reduction in both passenger and freight capacity. By the end of 2009, passenger capacity in international markets had shrunk 5\%. Freight capacity was down $10 \%$, and even more at its lowest point in mid2009. These capacity cuts, combined with the upturns in demand, led to load factors rising very sharply from their early 2009 lows. By the end of the year, load factors had reached record highs".

Consequently, the fewer international flights that were available achieved higher load factors than normal which accounts for the sudden improvement in the fuel efficiency (from $0.368 \mathrm{~L} / \mathrm{RTK}$ in 2009 to $0.342 \mathrm{~L} / \mathrm{RTK}$ in 2010) of international flights at that time. Once market conditions improved, passenger and cargo load factors returned to pre-GFC levels and the fuel efficiency value of international flights slowly returned to its 2008 values. It peaked at around $0.371 \mathrm{~L} / \mathrm{RTK}$ in 2014 , but from then on, a gradual improvement is evident.

It is also possible, with the data presented in Table 4, to assess the relative contribution non-scheduled services

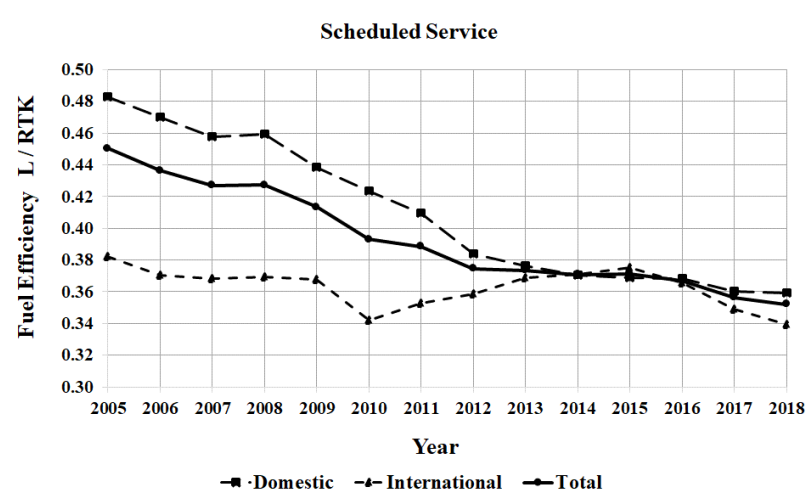

Figure 2. Domestic, international, and total Fuel Efficiency Values (Litres/RTK) for scheduled U.S. air carriers on an annual basis: $2005-2018$ make to U.S. aviation, and also to investigate the fuel efficiency of this sector. In a given year between 2005 and 2018, non-scheduled services accounted for anything from $3.5 \%$ to $8 \%$ of the total fuel volume consumed whilst carrying between $2.5 \%$ to $5 \%$ of total RTKs in the U.S. market. It is evident that until 2015, non-scheduled operations were significantly less fuel-efficient than scheduled services and delivered poor returns on a L/RTK performed basis (see Figure 3).

From Figure 3, it is apparent the non-scheduled sector performed poorly in terms of fuel efficiency from 2005 to 2015, and especially between 2010 to 2014 in the international arena; understanding the reason why is harder to explain. It is noted that the fuel efficiency in the domestic and international sectors diverged significantly in 2007 and has only begun to converge again since 2014. One major characteristic of the non-scheduled industry is that companies generally operate on the basis of full-plane sales. Hence the poor fuel efficiency demonstrated in Figure 3 cannot simply be ascribed to poor passenger or cargo load factors. However, for the period in question, poor load factors do, in fact, appear to be the underlying reason why the non-scheduled international sector performed so badly in comparison with the non-scheduled domestic sector. Between 2008 and 2013 the L/RTK performed in the non-scheduled international sector were more than double those achieved by the corresponding non-scheduled domestic sector. Whilst there is no single identifiable cause for this spike in L/RTK, the following two factors are offered as the most likely contributors:

- between 2010 to 2014 there were a lot of military ferry flights to the Middle East (Iraq, Syria, Yemen) and Afghanistan to support U.S. and coalition force military operations. Delivering hardware and personnel took priority over mission load factors and the fuel efficiency suffered accordingly. This is borne out by the RTK proportion of non-scheduled international military flights (service class $N+R$ ) compared with the total number of non-scheduled international flights, which exceeded $40 \%$ in 2010 and 2011, but

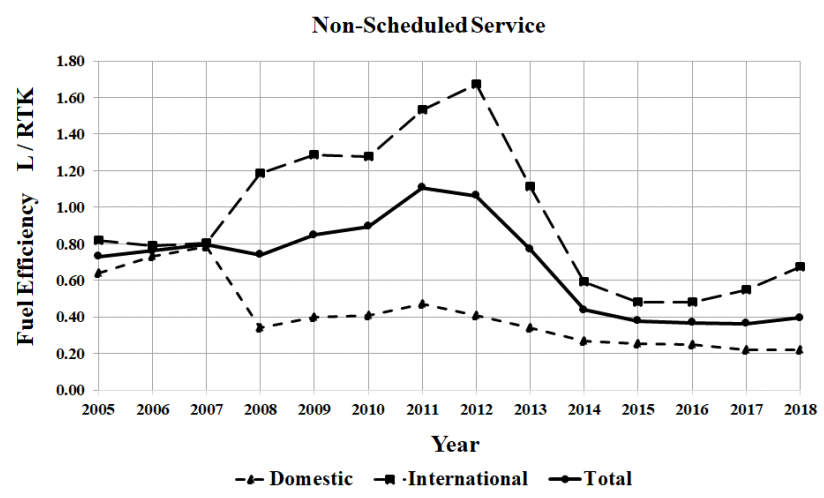

Figure 3. Domestic, international, and total Fuel Efficiency Values (Litres/RTK) for non-scheduled U.S. air carriers on an annual basis: 2005-2018 
then gradually decreased to $27 \%$ in $2012,12 \%$ in 2013, and only 4\% in 2014 (BTS Schedule T-2, 2019);

- As a knock-on consequence of the GFC, the RTK proportion for non-scheduled international freight flights (service class $L+N+P+R$ ) compared with the total number of non-scheduled international flights plummeted in 2011-2012 by some $22 \%$. Again, whilst capacity was also downsized, the net effect here was a drop in freight load factors which adversely affected the fuel efficiency during 2011-2012 (BTS Schedule T-2, 2019).

\section{Discussion}

The Air Transport Action Group (2018) recently claimed, "an average annual fuel efficiency of $2.1 \%$ has been achieved across the [world-wide] fleet between 2009 and 2016". The work presented here suggests a slightly less upbeat view based on a detailed review of U.S. air carriers, although a similar analysis of other aviation-centric markets, such as Europe, China, and S.E. Asia ${ }^{11}$ might help account for the difference.

The use of biofuels has also received much attention in the literature (IATA, 2015). However, its use does not alter the fuel efficiency of a given aircraft, but it does help to reduce net emissions in line with IATA's (2009) second and third goals. The US BTS Schedule P-12(a) (2019) does not distinguish between the types of fuel (fossil fuel, biofuel) consumed, and further investigation shows that only one US airline - United Airlines - currently uses biofuel in regular operations. The quantities of biofuel used, whilst cost-competitive and on a commercial scale, are miniscule compared to fossil fuel usage (Australian Aviation, 2019), so it is safe to infer that the fuel quantities shown in Table 2 effectively refer only to fossil fuels. However, the gradual adoption of sustainable aviation fuel is a promising development and one which will play an increasingly important role in helping airlines reduce aviation emissions over the next 30 years.

According to historic trends, civil aircraft fuel efficiency has improved significantly in the past 40 years (IATA, 2010). Kharina and Rutherford (2015) estimated that the average fuel burn of new aircraft has reduced by approximately 45\% from 1968 to 2014 . The primary drivers that help improve an aircraft's fuel-efficiency (Air Transport Action Group, 2010) are

(i) Advances in propulsive efficiency are:

- All modern subsonic passenger jet aircraft use complex high-bypass turbofan engines. The continuing development of such engines, for example advanced highbypass turbofans, geared turbofans, and even open-rotor engines (Blockley et al., 2016; Pratt \& Whitney Division, 2019; Benito \& Alonso, 2018), promises to deliver substantial improvements in aviation fuel efficiency. It is noted that gains in engine efficiency eclipse any other

\footnotetext{
${ }^{11}$ The lack of publicly available databases that share relevant information from these regions is regrettable.
}

gains that may be made (see (ii) and (iii)), as typified by the new generation of Airbus A320neo aircraft. These are essentially existing A320 airframes, albeit somewhat refined, complemented by newer, more efficient engines. It is claimed the new type delivers a $15 \%$ improvement in fuel efficiency (Stemart, 2015) - it is obviously the engines that are delivering the majority of this level of improvement. Boeing has adopted a similar approach with its 737MAX program.

(ii) Drag reduction through aerodynamic refinements:

- This includes various types of wing optimisation, the addition of blended winglets to reduce tip vortex drag, novel layouts or configurations, morphing structures, and even the application of riblets (García-Mayoral \& Jiménez, 2011). NASA (2017) gives an overview of current and future research in this area.

(iii) Reducing the overall weight of the aircraft:

- This includes simplifying the onboard systems, the use of light-weight seats and cabin/galley equipment, reducing the weight of the auxiliary power unit and the belly-hold freight containers, and of course the adoption of carbon fibre composites for airframe primary structure (Hamerton \& Mooring, 2012; Sádaba et al., 2015). Additive manufacture, or $3 \mathrm{D}$ printing, is also slowly finding its way into aerospace applications (Joshi \& Sheikh, 2015) where it promises to help reduce aircraft weight while increasing customization and overall construction efficiency.

When the technological advances described in (i) (iii) above are combined into a state-of-the-art twin-engine passenger aircraft, the fuel efficiency gains over the previous generation of comparable aircraft could possibly amount to $15 \%-20 \%$ (Stemart, 2015). Further technological advances at an operational level, such as optimising an airline's network, along with improvements in navigation and air traffic management (Airservices Australia, 2013), can also help airlines reduce flight times and fuel consumption on long-haul flights (Green Air, 2013).

Many of these technological developments have occurred in the past 5-10 years, and are reflected in the associated trends in fuel-efficiency improvement. As one of the wealthiest nations on earth, U.S. airlines tend to operate a relatively young fleet of passenger aircraft both domestically and internationally, and thus they reap the benefits of all the aforementioned efficiency gains as they become available. However, since other aviation regions worldwide are unlikely to match the same uptake of new aircraft as seen in the U.S., it would be misleading to extrapolate the current promising results to a global level. Indeed, as worldwide airlines update their individual fleets, it is common for many older aircraft to be on-sold to lower-income aviation markets in developing countries, or re-purposed as passenger-to-freighter conversions. Hence, whilst technological improvements are just managing to keep U.S. air carriers abreast of IATA's ambitious target (CNG2020, n.d.), at a global level the dominance of types older than 10 years will continue to be a drag on global aircraft fuel efficiency (IATA, 2018a). 


\section{Conclusions}

This paper has examined the progress in fuel efficiency made by U.S. air carriers over the past decade. A longer time-span, from 2005 to 2018 has been considered, which helps establish the longer-term trend and smooths any irregularities, like the sudden market downturn in the aftermath of the global financial crisis. Whilst nonscheduled services contribute less than $10 \%$ of total U.S. aviation, the fuel efficiency of this sector has, until recently, been significantly worse than that demonstrated by the scheduled sector. This has, in turn, adversely affected the overall performance of the total aviation industry in the U.S. However, some recent welcome improvements in L/RTK within the non-scheduled sector bode well for the future.

U.S. air carriers have achieved an overall $1.52 \%$ annual fuel efficiency improvement over the years 2010 to 2018, which accords with the IATA-agreed annual 1.5\% fuel efficiency improvement targeted for the decade from 2010 to 2020. This result suggests that U.S. air carriers are very likely to meet, or even marginally exceed, their IATA-agreed target by 2020. By inference, and subject to the caveats discussed in Section 1, it can be postulated that the remainder of the world's airlines will also achieve a similar result. Whilst improvements in aviation fuel efficiency continue, despite the increased numbers of passengers and flights, it is recognized this trend cannot continue indefinitely and some natural limit will soon be reached. This reinforces the urgency of all ICAO contracting states to actively pursue IATA's (2009) second and third goals, namely carbon neutral growth from 2020 , and a reduction of $50 \%$ in net emissions by 2050 compared to 2005 levels. Whilst these ambitions involve many challenges which the global aviation industry has yet to solve, there are indications of progress that are encouraging, such as the recent second ICAO Conference on Aviation Alternative Fuels (CAAF2, 2017), which fully endorsed the 2050 ICAO Vision for Sustainable Aviation Fuels. Widespread adoption of initiatives like this will go a long way towards ensuring a carbon-neutral future for aviation (Staples et al., 2018).

\section{Author contributions}

Nicholas Bardell conceived the study. Kit Sum Cho and Guanying Li were responsible for the design and development of the data analysis and collection. Nicholas Bardell, Kit Sum Cho and Guanying Li were responsible for data interpretation. Kit Sum Cho and Guanying Li wrote the first drafts of the article, which Nicholas Bardell subsequently edited, refined and rendered in this final form.

\section{Disclosure statement}

All the authors of this paper hereby declare they have no competing financial, professional, or personal interests from other parties.

\section{References}

Airservices Australia. (2013). Australian organised track structure - AUSOTS. https://www.airservicesaustralia.com/ausots/ whatisaflextrack.asp

Air Transport Action Group. (2010). Beginner's guide to aviation efficiency. http://large.stanford.edu/courses/2017/ph240/ chhoa1/docs/atag-nov10.pdf

Air Transport Action Group. (2018). Aviation benefit beyond borders. https://aviationbenefits.org/media/166344/abbb18_fullreport_web.pdf

Airbus. (2019). Global Market Forecast 2019-2038. https://www. airbus.com/aircraft/market/global-market-forecast.html

Australian Aviation. (2019). United airlines leads charge on biofuel commitment. https://australianaviation.com.au/2019/05/ united-airlines-leads-charge-on-biofuel-commitment/

Babikian, R., Lukachko, S. P., \& Waitz, I. A. (2002). The historical fuel efficiency characteristics of regional aircraft from technological, operational, and cost perspectives. Journal of Air Transport Management, 8(6), 389-400. https://doi.org/10.1016/S0969-6997(02)00020-0

Bardell, N. S., \& Yue, H. (2018, Oct 31-Nov 02). A discussion about how efficiently the major US airlines are using their domestic fleets of Boeing 737-800 aircraft. 40th Australasian Transport Research Forum. Darwin, Australia.

Benito, A., \& Alonso, G. (2018). 4 - Aircraft design. In A. Benito \& G. Alonso (Eds.), Energy efficiency in air transportation, butterworth-heinemann (pp. 45-75). http://www.sciencedirect.com/science/article/pii/B9780128125816000041

Blockley, R., Agarwal, R., Collier, F., Schaefer, A., \& Seabridge, A. (2016). Green aviation. John Wiley \& Sons.

Boeing. (2019). Commercial market outlook 2019-2038. https:// www.boeing.com/commercial/market/commercial-marketoutlook/

Budd, L., Griggs, S., \& Howarth, D. (2013). Sustainable aviation futures. Emerald Group Publishing. https://doi.org/10.1108/ S2044-9941(2013)0000004018

BTS Schedule T-100. (2019). United States Department of Transportation, Bureau of Transportation Statistics, Air Carrier Statistics (Form 41 Traffic). U.S. Carriers. http://www.transtats.bts.gov

BTS Schedule P-12(a). (2019). Bureau of Transportation Statistics (BTS), Airline Fuel Cost and Consumption (U.S. Carriers All), United States Department of Transportation, Bureau of Transportation Statistics, Air Carrier Financial: Schedule P12(a). https://www.transtats.bts.gov/fuel.asp?pn=1

BTS Schedule T-2. (2019). Bureau of Transportation Statistics (BTS), Schedule T-2, United States Department of Transportation, Bureau of Transportation Statistics, Air Carrier Summary: T2: U.S. Air Carrier Traffic And Capacity Statistics by Aircraft Type. https://www.bts.gov/browse-statistical-products-and-data/bts-publications/data-bank-21-form-41-schedule-t-2-t-100

CAAF2. (2017, 11-13 October). Second ICAO Conference on Aviation and Alternative Fuels (CAAF2). Mexico City, Mexico. https://www.icao.int/meetings/caaf2/pages/default.aspx

CNG2020. (n.d.). Resolution on the implementation of the aviation "CNG2020" strategy. 69th Annual General Meeting of the International Air Transport Association. Geneva. https:// www.iata.org/pressroom/pr/Documents/agm69-resolutioncng2020.pdf

Cui, Q., \& Li, Y. (2015). Evaluating energy efficiency for airlines: An application of VFB-DEA. Journal of Air Transport Management, 44-45, 34-41.

https://doi.org/10.1016/j.jairtraman.2015.02.008 
Cui, Q., \& Li, Y. (2016). Airline energy efficiency measures considering carbon abatement: A new strategic framework. Transportation Research Part D: Transport and Environment, 49, 246-258. https://doi.org/10.1016/j.trd.2016.10.003

Durso, J. C. (2007). An introduction to DOT Form 41 web resources for airline financial analysis. https://rosap.ntl.bts.gov/ view/dot/16264/dot_16264_DS1.pdf?

Engelman, R. (2013). Beyond sustainable. In State of the world 2013: is sustainability still possible? (pp. 3-16) Island Press/ Center for Resource Economics, Washington, DC. https://doi.org/10.5822/978-1-61091-458-1_1

García-Mayoral, R., \& Jiménez, J. (2011). Drag reduction by riblets. Philosophical Transactions of the Royal Society, 369, 1412-1427. https://doi.org/10.1098/rsta.2010.0359

Gössling, S., \& Upham, P. (2009). Climate change and aviation: Issues, challenges and solutions. Earthscan.

Green Air. (2013). Airservices Australia's Flex Tracks programme completes 10 years of fuel and emissions savings for Emirates. https://www.greenaironline.com/news.php?viewStory=1797

Hamerton, I., \& Mooring, L. (2012). 7 - The use of thermosets in aerospace applications (pp. 189-227). In Q. Guo (Ed.), Thermosets, 2012, 189-227. http://www.sciencedirect.com/ science/article/pii/B9780857090867500079

Hassan, M., Pfaender, H., \& Mavris, D. (2018). Probabilistic assessment of aviation $\mathrm{CO}_{2}$ emission targets. Transportation Research Part D: Transport and Environment, 63, 362-376. https://doi.org/10.1016/j.trd.2018.06.006

Hileman, J., Katz, J. B., Mantilla, J. G., \& Fleming, G. (2008, 14-19 September). Payload fuel energy efficiency as a metric for aviation environmental performance. 26th International Congress of Aeronautical Sciences. Anchorage, Alaska, USA. Paper ICAS 2008-4.7.4

IATA. (2007). IATA calls for a zero emissions future. https:// www.iata.org/pressroom/pr/Pages/2007-06-04-02.aspx

IATA. (2009). Resolution on implementation of the aviation carbon-neutral growth (CNG2020) strategy. https://www. iata.org/contentassets/3a0afea48e6e400f90e748edcf43d3c3/ agm69-resolution-cng2020.pdf

IATA. (2010, June). Giovanni Bisignani director general \& CEO International Air Transport Association Annual Report 2010. 66th Annual General Meeting. Berlin. https://www. iata.org/about/Documents/IATAAnnualReport2010.pdf

IATA (2015). IATA Sustainable aviation fuel roadmap (1st ed.). International Air Transportation Association: Montreal, Geneva. https://www.iata.org/contentassets/d13875e9ed784f75bac90f000760e998/safr-1-2015.pdf

IATA. (2018a). World air transport statistics. https://www.iata.org/ publications/store/Pages/world-air-transport-statistics.aspx

IATA. (2018b). Air passenger market analysis December 2018. https://www.iata.org/publications/economics/Reports/paxmonthly-analysis/passenger-analysis-dec-2018.pdf

IATA. (2018c). Air freight demand ends year Up 3.5\%, despite softening late 2018. https://www.iata.org/pressroom/pr/Pages/2019-02-06-01.aspx

IATA. (2019). About us. https://www.iata.org/about/Pages/index.aspx

ICAO. (2009, 23-27 November). Review of the classification and definitions used for civil aviation activities. Tenth Session of the Statistics division, STA/10-WP/7. Montreal.

ICAO. (2010). International civil aviation organization. Assembly Resolutions in Force (as of 8 October 2010). Doc 9958, ISBN 978-92-9231-773-7.
ICAO. (2017). ICAO Council adopts new $\mathrm{CO}_{2}$ emissions standard for aircraft (Para 4). https://www.icao.int/newsroom/ pages/icao-council-adopts-new-co2-emissions-standardfor-aircraft.aspx

ICAO. (2019). Member states. https://www.icao.int/MemberStates/Member\%20States.Multilingual.pdf

Joshi, S.C., \& Sheikh, A. A. (2015). 3D printing in aerospace and its long-term sustainability. Virtual and Physical Prototyping, 10(4), 175-185. https://doi.org/10.1080/17452759.2015.1111519

Kharina, A. \& Rutherford, D. (2015). Fuel efficiency trends for new commercial jet aircraft: 1960 to 2014. International Council on Clean Transportation, Washington, DC. https:// theicct.org/sites/default/files/publications/ICCT_Aircraft-FETrends_20150902.pdf

Lee, J. J., Lukachko, S. P., Waitz, I. A., \& Schafer, A. (2001). Historical and future trends in aircraft performance, cost, and emissions. Annual Review of Energy the Environment, 26(1), 167-200. https://doi.org/10.1146/annurev.energy.26.1.167

Lumbroso, A. (2019). Aviation liberalisation: What headwinds do we still face? Journal of Air Transport Management, 74, 22-29. https://doi.org/10.1016/j.jairtraman.2018.09.003

Miyoshi, C., \& Merkert R. (2010). Changes in carbon efficiency, unit cost of firms over time and the impacts of the fuel pricean empirical analysis of major European airlines. Porto, Portugal.

Nangia, R. (2006). Efficiency parameters for modern commercial aircraft. The Aeronautical Journal, 110(110), 495-510. https://doi.org/10.1017/S0001924000001391

NASA. (2017). Improving aerospace vehicle efficiency. https://www. nasa.gov/feature/improving-aerospace-vehicle-efficiency

Nelson, E. S. \& Reddy, D. R. (2018). Green aviation: reduction of environmental impact through aircraft technology and alternative fuels. Sustainable Energy Developments, CRC Press, London, UK. https://doi.org/10.1201/b20287

Peeters, P., Middel, J., \& Hoolhorst, A. (2005). Fuel efficiency of commercial aircraft: an overview of historical and future trends. NLR-CR-2005-669.

Sádaba, S., Martínez-Hergueta, F., Lopes, C. S., Gonzalez, C., \& Llorca, J. (2015). 10 - Virtual testing of impact in fiber reinforced laminates. In P. W. R. Beaumont, C. Soutis, \& A. Hodzic (Eds.), Structural integrity and durability of advanced composites (pp. 247-270). Woodhead Publishing. http://www. sciencedirect.com/science/article/pii/B9780081001370000109

Staples, M. D., Malina, R., Suresh, P., Hileman, J. I., \& Barrett, S. R. H. (2018). Aviation $\mathrm{CO}_{2}$ emissions reductions from the use of alternative jet fuels. Energy Policy, 114, 342-354. https://doi.org/10.1016/j.enpol.2017.12.007

Stemart, C. (2015). Fuel and flight efficiency services by airbus. AACO 7th Aviation Fuel Forum. Dubai, UAE.

T-100 Traffic Reporting Guide. (2007). U. S. Department of Transportation.

United Nations. (1987). Report of the World Commission on Environment and Development: Our Common Future.

United Technologies Corporation - Pratt \& Whitney Division. (2019). Pratt \& Whitney GTF engine. https://www.pw.utc. com/products-and-services/products/commercial-engines/ Pratt-and-Whitney-GTF-Engine/

Zhang, A., Hanaoka, S., Inamura, H., \& Ishikura, T. (2008). Low-cost carriers in Asia: Deregulation, regional liberalization and secondary airports. Research in Transportation Economics, 24(1), 36-50.

https://doi.org/10.1016/j.retrec.2009.01.001 